Article

\title{
Cyclic Fatigue, Torsional Resistance, and Angular Deflection of Two Heat-Treated Files: M-Wire Versus New F-Wire Technology
}

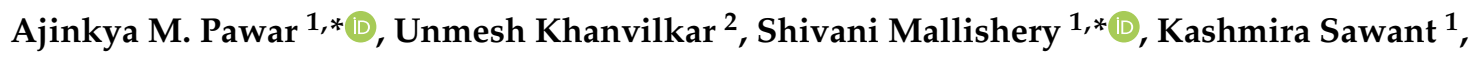 \\ Ricardo Machado ${ }^{3}\left(\mathbb{D}\right.$, Gianluca Plotino ${ }^{4}\left(\mathbb{D}\right.$, Alexander Maniangat Luke ${ }^{5}\left(\mathbb{D}\right.$, Simy Mathew ${ }^{6}(\mathbb{D}$, \\ Musab Hamed Saeed ${ }^{5}$ and Krishna Prasad Shetty ${ }^{5}$ \\ 1 Department of Conservative Dentistry and Endodontics, Nair Hospital Dental College, Mumbai 400008, \\ India; kashmiraswnt@gmail.com \\ 2 Department of Conservative Dentistry and Endodontics, D Y Patil School of Dentistry, Nerul, Navi Mumbai, \\ Maharashtra 400706, India; unmesh22@yahoo.com \\ 3 Clinical Practice Limited to Endodontics, Navegantes, Santa Catarina 88370-100, Brazil; \\ ricardo.machado.endo@gmail.com \\ 4 Private Practice, Grande Plotino Torsello-Studio do Odontoiatria, Via Calabria, 25, 00198 Rome, Italy; \\ endo@gianlucaplotino.com \\ 5 Department of Clinical Sciences, Ajman University, College of Dentistry, Ajman 346, UAE; \\ a.luke@ajman.ac.ae (A.M.L.); m.saeed@ajman.ac.ae (M.H.S.); kprasad11@gmail.com (K.P.S.) \\ 6 Department of Basic Sciences, Ajman University, College of Dentistry, Ajman 346, UAE; \\ s.mathew@ajman.ac.ae \\ * Correspondence: ajinkya@drpawars.com (A.M.P.); sshivani96@gmail.com (S.M.); \\ Tel.: +91-9867636233 (A.M.P.); +91-8080844677 (S.M.)
}

Received: 15 September 2020; Accepted: 10 October 2020; Published: 12 October 2020

check for updates

\begin{abstract}
The cyclic fatigue, torsional resistance, and angular deflection of a new Fire-Wire rotary file (CricENDO) were compared. A total of 20 files of each type were tested. Cyclic fatigue testing was performed for each group $(n=10)$ by measuring the number of cycles to fracture $(\mathrm{NCF})$ in an artificial stainless-steel canal $\left(60^{\circ}\right.$ angle of curvature, with a 6-mm radius) for each group. The torque and angle of rotation at the failure of each group $(n=10)$ were measured according to ISO 3630-1. The fractured surfaces were examined using scanning electron microscopy. Statistical analysis was carried out utilizing Student's t-test at a significance level set at 5\%. The Fire-Wire CricENDO rotary files were associated with a significantly higher number of cycles to fracture and time to failure (in seconds) compared to the M-Wire Protaper Next $(p<0.05)$. A significantly higher angular deflection to fracture was observed for CricENDO compared to Protaper Next $(p<0.05)$. The new Fire-Wire CricENDO rotary files exhibit higher cyclic fatigue resistance and angle of rotation to fracture than M-Wire Protaper Next. Without warning, file fracture may occur as a result of cyclic fatigue, torsional stress, or a combined effect of both. CricENDO rotary files may be an effective alternative in curved root canals as they exhibited elevated cyclic and torsional resistance. It will be helpful in eliminating one of the reasons for file fracture during the root canal treatment.
\end{abstract}

Keywords: angular deflection; cyclic fatigue; Fire-Wire; fracture; M-Wire; torsional resistance

\section{Introduction}

The key aspect of an endodontic therapy is to sustain or re-establish the health of periapical tissues by cleaning, shaping [1], and filling [2] the root canals. Cleaning and shaping are achieved through the associated use of files and chemical substances (irrigating solutions and intracanal dressings) [1]. 
Then, the canals must be filled to maintain the cleaning obtained through the previous stages, trap the remaining microorganisms, interrupt the supply of nutrients necessary for their survival, and avoid contamination or recontamination [2].

Irrigation and intracanal dressings have proven to be relatively effective for the success of endodontic treatment [3,4]. An equivalent cannot be said about the endodontic files. Procedure errors $[5,6]$ and untouched root canal walls $[7,8]$ often occur in treatments using endodontic files. For this reason, researchers are continually attempting to develop new files with the aim of increasing their performance.

Among procedural errors that occur during the chemo-mechanical preparation, instrument fracture is the most frequent $[9,10]$. It is commonly assumed that instrument fractures are often caused by two different mechanisms-torsional and cyclic failures. Cyclic failure results from constant tension and compression stress on the region of maximal root canal curvature. Torsional failure occurs if the tip of the file binds into the canal because the instrument shank continues to rotate; thus, the torque surmounts the plastic limit of the metal. In the course of manufacture of files, other elements like the angle of rotation, cross-sectional design, metallurgical properties, and thermomechanical processes can also contribute to the mechanical properties $[9,11]$.

Off late, a new super elastic M-Wire technology was employed to manufacture Protaper Next (Dentsply Sirona, Ballaigues, Switzerland). These files have an off-centered rectangular cross-section with only two cutting/contact points (when in rotation within the canal). This design was executed to decrease the strain on the file when used for instrumenting the root canal [12].

The CricEndo system (CricDental Pvt. Ltd., Mumbai, India) is manufactured with a new thermal treatment called F-Wire. According to the manufacturer this heat treatment increases the flexural strength and flexibility of the instrument. The characteristics, namely, deformation and strength of the metal alloys could be changed with the said heat treatment. These files have a convex triangular cross-section and a continuous taper of $4 \%(\mathrm{C} 1, \mathrm{C} 2, \mathrm{C} 3, \mathrm{SF} 1$, and SF2) or $6 \%$ (E1 and E2). Consistent with the manufacturer's information, the system has higher cyclic and torsional resistance to fracture compared to instruments manufactured with M-Wire technology.

This study aimed to compare cyclic fatigue, torsional resistance, and angle of distortion of the CricEndo (E2) and Protaper Next (X2) files. The null hypothesis tested was that there are no differences between the two files for the variables being compared.

\section{Materials and Method}

The sample size calculation was based on the results of previous study [13]. Using an alpha ( $\alpha)$ level of $0.05(5 \%)$ and a beta $(\beta)$ level of $0.20(20 \%)$ (i.e., power $=80 \%$ at a $5 \%$ significance level) and a difference between the two groups of $50 \pm 51.3$, the minimum estimated sample size was 10 samples per group but we increased it to 20 samples per group.

Initially, 40 endodontic rotary files with an equivalent tip size (25) and length $(25 \mathrm{~mm})$ but manufactured with different thermal treatments (F-Wire and M-Wire) were selected for this study (CricEndo E2 and Protaper Next X2 files, respectively). Twenty files (10 per group) were used for cyclic fatigue resistance tests. The apparatus used for this part of the study was analogous thereto that already employed by Plotino et al. [13]. In brief, the apparatus consisted of a main frame, moving plastic support for the endodontic motor handpiece (XSmart Plus; Dentsply Maillefer, Ballaigues, Switzerland), and a stainless-steel block with a uniform artificial canal. The canal of this device was standardized by replicating the file size and taper, $60^{\circ}$ angle of curvature, and 5-mm radius of curvature [14]. From the tip of the file, the center of the curvature was maintained at $5 \mathrm{~mm}$. The handpiece of the endodontic motor was mounted on a moving device that allowed precise and reproducible movements of every file to be tested within the canal, consistent with the manufacturer's instructions. To scale back the friction, a synthetic oil designed for the lubrication of mechanical parts (Super Oil; Singer Co Ltd., NJ, USA) was used $[15,16]$. The temperature of the experiment was maintained at $37^{\circ} \mathrm{C}$. The time of motor activation was recorded employing a digital timer, and the time was stopped as soon as a fracture was 
detected visually and/or audibly. This step of the procedure was video-recorded, and therefore the recordings were observed to make sure that the recorded time of instrument fracture was accurate [16]. Then, the video recordings were used to identify the number of cycles to fracture (NCF). The mean lengths of the fractured segments of the files were also recorded to evaluate whether the instrument was positioned correctly inside the canal curvature and whether the stresses induced on the two file types were similar.

Torsional resistance and angular deflection were evaluated according to ISO 3630-1 (1992) [16,17]. For this, 20 more files (10 per group) were used. The apical $3 \mathrm{~mm}$ of every file was clamped employing a chuck connected to a torque-sensing device (Sabri Dental Enterprises, Inc., Downers Grove, IL, USA), after which the shaft of the file was fastened onto an opposing chuck. The rotational speed of the instruments was set in clock-wise direction ( $2 \mathrm{rpm})$, and employing that setting, the maximum torque, and angular deflection until fracture of the instrument were ascertained.

\section{Statistical Analysis}

Initial data were analyzed using a Shapiro-Wilk normality test, which revealed a normal distribution. For this reason, a parametric test (Student's t-test) was applied to identify whether there were statistical differences between the systems/files. Post-hoc pair-wise comparisons were performed using the Tukey test for multiple comparisons. All statistical analyses were performed using Biostat 4.0 Software (Mamirauá Institute, Belém, Brazil) with a significance level of 95\%.

\section{Results}

The CricEndo E2 files exhibited significantly higher NCF and time to fracture than the Protaper Next X2 files $(p<0.01$; Table 1). No statistically significant difference was observed in the mean length of the fractured fragments of the files $(p>0.05$; Table 1$)$. No difference was found between the groups for the torque needed to fracture the files $(p>0.05$; Table 2$)$. Lastly, the distortion angles of the CricEndo X2 files were significantly higher than Protaper Next X2 files $(p<0.01$; Table 2). Scanning Electron Microscope (SEM) images demonstrated characteristic dimpling of the entire fractured surfaces, microvoids, fatigue striations, and overloaded areas causing cyclic fatigue failure (Figure 1).

Table 1. Data obtained after cyclic fatigue test.

\begin{tabular}{cccc}
\hline File & NCF \pm SD & $\begin{array}{c}\text { Time to Fracture } \\
\text { (Seconds } \pm \text { SD) }\end{array}$ & $\begin{array}{c}\text { Mean Length of the Fractured } \\
\text { Fragments (Millimeters } \pm \text { SD) }\end{array}$ \\
\hline $\begin{array}{c}\text { CricEndo E2 } \\
\text { (number of files-10) }\end{array}$ & $667 \pm 33^{\mathrm{a}}$ & $155 \pm 17^{\mathrm{c}}$ & $5.51 \pm 0.34^{*}$ \\
\hline $\begin{array}{c}\text { Protaper Next X2 } \\
\text { (number of files-10) }\end{array}$ & $498 \pm 46^{\mathrm{b}}$ & $101 \pm 24^{\mathrm{d}}$ & $5.28 \pm 0.16^{*}$ \\
\hline
\end{tabular}

$\mathrm{NCF}$, number of cycles to fracture; SD, standard deviation. Different lower case letters in the same column represent statistically significant differences between groups (Student's $t$-test; $p<0.01$ ). ${ }^{*}$ There was no significant difference in length of fracture fragment between files (Student's $t$-test; $p>0.05$ ).

Table 2. Data obtained after torsional resistance tests.

\begin{tabular}{lcc}
\hline \multicolumn{1}{c}{ File } & Torque (gf/cm \pm SD) & Distortion Angle \pm SD \\
\hline CricEndo E2 (number of files-10) & $168 \pm 08^{*}$ & $389 \pm 28^{\mathrm{a}}$ \\
\hline Protaper N X2 (number of files-10) & $153 \pm 11^{*}$ & $235 \pm 13^{\mathrm{b}}$ \\
\hline $\begin{array}{l}\text { g, gram; f, force; cm, centimeters; SD, standard deviation. }{ }^{*} \text { There was no significant difference in torque resistance } \\
\text { between files (Student's } t \text {-test; } p<0.01 \text { ). Different lower case letters in the same column represent statistically } \\
\text { significant differences between groups (Student's } t \text {-test; } p<0.01 \text { ). }\end{array}$
\end{tabular}



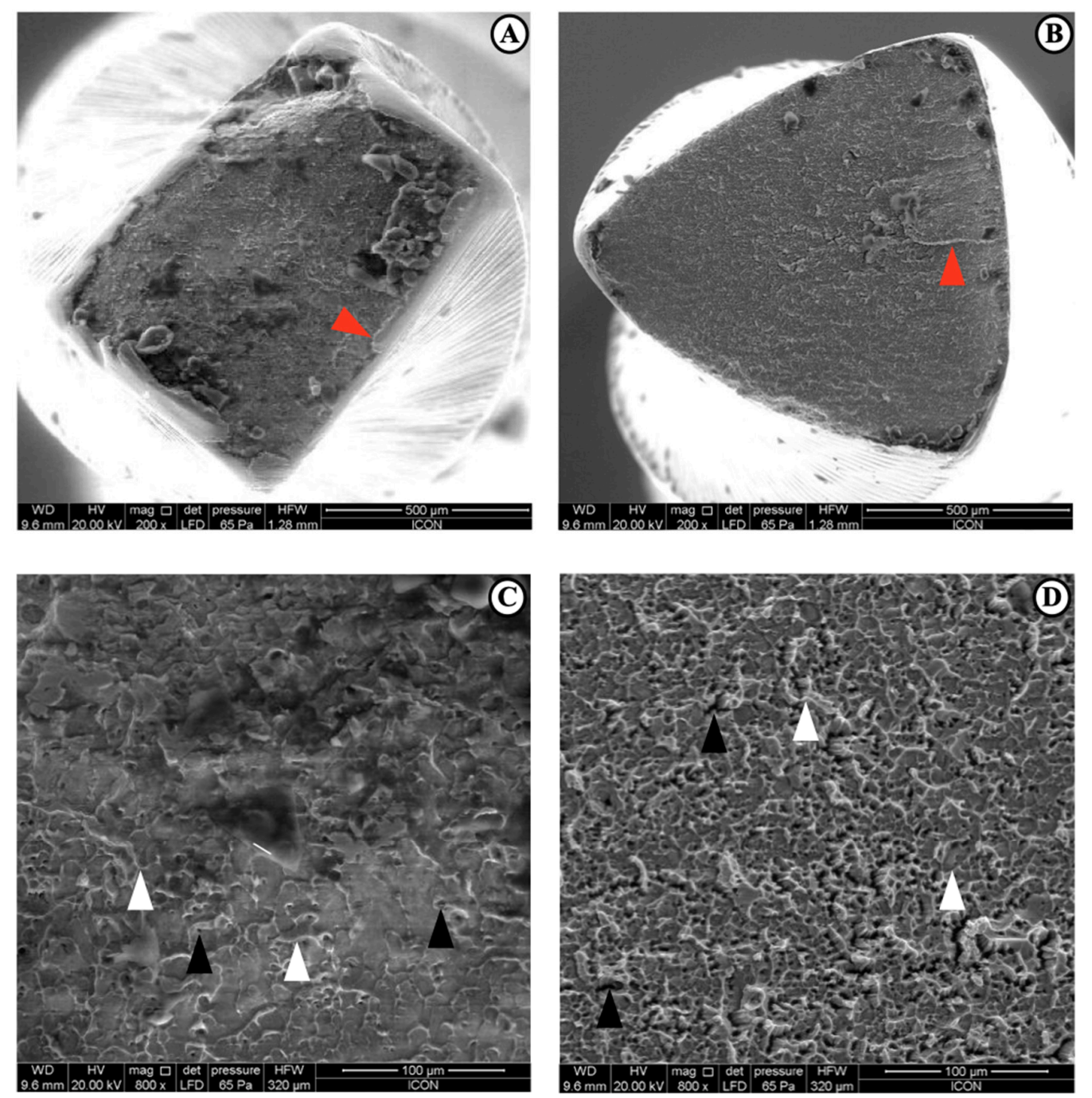

Figure 1. Representative scanning electron micrograph of the fractured surface exhibiting fatigue zones, overload zone, dimples, and microvoids under low magnification $(\times 200)$ : (A) Protaper NEXT, (B) CricENDO. Under higher magnification $(\times 800)$ : the fractured surface exhibited as irregular, consistent rough dimpled (white arrow), microporous, microvoids (black arrow), and fatigue striations (red arrow) with no microcracks: (C) Protaper NEXT, (D) CricENDO.

\section{Discussion}

Instrument fracture is the most common accident that occurs during the chemo-mechanical preparation when NiTi file systems are used [9-11]. Different thermal treatments seem to decrease its incidence $[18,19]$, however, they are not able to eliminate it. Cyclic fatigue, torsional resistance, and angle of distortion are important points for a better understanding of file fracture [9-11]. Therefore, the present study evaluated these variables comparing a new endodontic rotary file system heat-treated by new technology (CricEndo E2/F-Wire) with a traditional system heat-treated by a well-known technology (Protaper Next X2/M-Wire). The null hypothesis was rejected following significant differences between the two instruments.

The type of NiTi alloy used, cross-sectional shape and area, core diameter, taper, tip size of the instrument, and manufacturing processes of the files are the determinant factors for cyclic fatigue, torsional resistance, and angle of rotation [10]. Planning to control these biases, instruments with similar designs, and the same length $(25 \mathrm{~mm})$ were used. Still, it is important to notice that in similar 
cyclic fatigue tests, friction among the file, and artificial root canal walls may cause heat generation hence, a lubricant was used [15,16].

Regarding torsional resistance and angular deflection especially, an extremely important point is the length of the clamped instrument tip during the tests as shown by Capar et al. [20]. The authors reported in this paper that the instrument was more susceptible to failure when $3 \mathrm{~mm}$ of the tip of the instrument is clamped compared to when $5 \mathrm{~mm}$ is clamped. Therefore, within the present study, the instruments were clamped at $3 \mathrm{~mm}$ from their tips.

CricEndo E2 files exhibited significantly higher NCF and time to fracture compared to Protaper Next X2 files $(p<0.01)$. As previously mentioned, the files tested herein had an equivalent tip (25) and length $(25 \mathrm{~mm})$. However, the taper is continuous for E2 CricEndo File $(6 \%)$ and variable for X2 Protaper Next file (6\% at 1 and $3 \mathrm{~mm}$ from the tip, $7 \%$ at 6 and $9 \mathrm{~mm}$ from the tip, $6 \%-13 \mathrm{~mm}$ from the tip, and $4 \%$ at $16 \mathrm{~mm}$ from the tip), considering that cycles to fracture decrease because of the increase in the diameter of the instrument [21,22]. Also, the superior performance might be due to the effect of annealing, internal stress relaxation, and smaller grain size. Heat treatment of alloy results in a three-dimensional alignment of crystal structure matrix leading to improved flexibility and fatigue resistance. Heat treatment results in better alignment of crystal structure leading to improved flexibility and fatigue resistance. The hybrid composition of both austenite and marten-site phases in different proportions may be a reason for increased flexibility with these files. Moreover, a hybrid microstructure with martensitic peaks provides resistance to crack propagation than a fully austenitic microstructure. These differences might explain this result. Greater flexibility may also result in the prevention of canal transportation whereas, higher cyclic fatigue may allow these files to navigate successfully in cases with severely curved root canals.

No statistically significant differences were observed between CricEndo E2 and Protaper Next X2 files for the torque needed to fracture them. Recall that the instruments were clamped at $3 \mathrm{~mm}$ from their tips according to the standardized method described in the ISO 3630-1, ADA/ANSI specifications number 28 (Figure 2) [23]. This was done to provide gradual application of torsional moment. The maximum torque and angular deflection when the file segment separated, are recorded. The endodontic files are more susceptible to failure when $3 \mathrm{~mm}$ of the tip of the instrument is clamped. With this clamping specification, the two instruments have equivalent diameter values (0.43), and both are heat-treated systems. These features may explain the dearth of differences between the two systems regarding the torque needed to fracture the files.

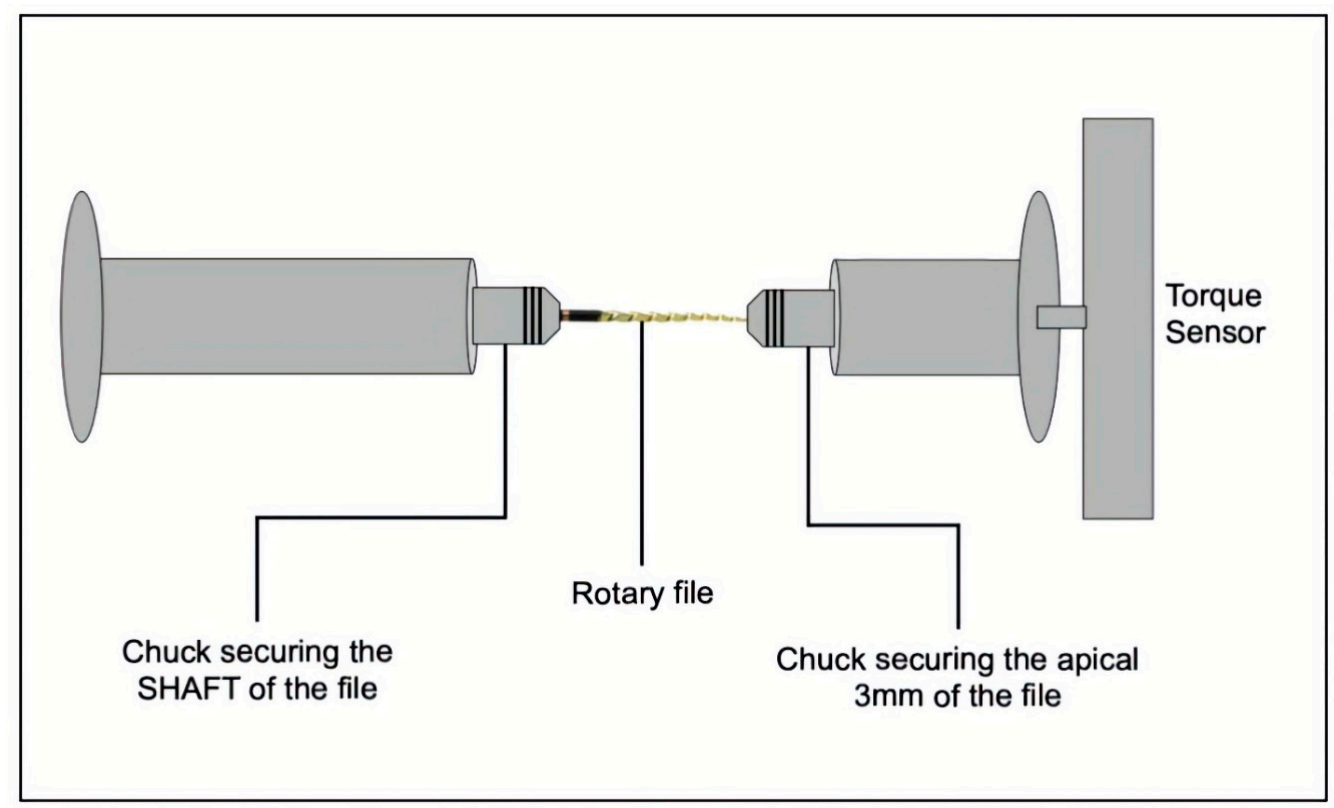

Figure 2. A schematic set-up for torsional testing of the files. 
CricEndo E2 files showed a significantly higher angle of distortion than Protaper Next X2 files $(p<0.01)$. However, the Protaper Next X2 file has an off-centered rectangular cross-section with two cutting edges and a variable taper12, whereas the CricEndo E2 file features a convex triangular cross-section and a continuous taper $(6 \%)$. These differences might explain the higher angle of distortion found for the Protaper Next X2 files. It is worth mentioning that in an exceedingly clinical scenario, visual analysis of the files from CricEndo system may assist the operator in identifying visible plastic deformation and clinicians may keep themselves away from using the file and thus avoid the resultant fracture $[16,23]$.

Several methodologies have been used to analyze cyclic fatigue of endodontic files, including a curved metal tube or a grooved block, movement of files against inclined planes, and 3-point bending [24]. Cyclic fatigue tests can be conducted either as a static or dynamic model. In the static model, there are no axial movements of the instrument in the artificial canal [25]. Conversely, the dynamic model includes back-and-forth or oscillating movements of the instrument in the canal $[26,27]$. The dynamic model has two advantages compared to the static model. First, the dynamic model is said to simulate the clinical environment [27]. Second, there is a wider distribution of stresses along the instrument in the dynamic model, while the static model causes concentration of stresses in a single area of the instrument [28]. However, the dynamic tests do not accurately replicate a clinical model since the instruments have much less oscillations clinically compared to dynamic static fatigue tests [27]. The employment of an artificial simulated canal in a stainless-steel block is the preferred method as evidenced in prior research. The inner diameter of the simulated canal was set to $1.5 \mathrm{~mm}$ to produce free rotation of the instruments with minimal torque values. This strategy already has been utilized in several previous studies [20,29], and can provide standardized conditions, and therefore, more confident results.

The SEM images exhibit significantly different fractured surface characteristics. At low magnification, multiple (Protaper Next) and few (CricEndo E2) ruptured aspects were found in the centrally located overload zones. At high magnification, the overload zones revealed evidence of dimpled rupture that occurred because of the coalescence of the microvoids in the overload zone resulting in the ultimate ductile fracture of the instruments.

Although this investigation made use of standardized and recognized methodologies, the results of this study should be evaluated with caution. It is important to notice that the performance of endodontic files is overestimated in standardized artificial conditions. The impacts of anatomical complexity should be considered within the clinical scenario. For example, it is often difficult to achieve instrumentation of infected oval root canals, because of the tendency to leave un-instrumented recesses [30].

While the study has presented some important findings, the aforementioned limitations must be a consideration when interpreting and extending the results. This study was executed on simulated root canal of stainless steel and the exact clinical condition like canal morphology could not be replicated. The simulated artificial canal curvature wherein the files were tested was two dimensional. Moreover, debris inside the root canal could be a modifying factor in the cyclic fatigue of the rotary files. The current study was carried out at room temperature. Future studies should explore the reported properties of the endodontic files at an intra-canal temperature setting, thus simulating clinical scenarios.

\section{Conclusions}

CricEndo E2 files (manufactured with F-Wire) exhibited significantly better results of cyclic fatigue and angular rotation to fracture compared to Protaper Next X2 files (manufactured with M-Wire). Both the files exhibited similar torque resistance. These findings suggest that F-Wire technology may reduce the possibilities of file fractures due to cyclic fatigue. However, more studies are needed to prove this hypothesis. 
Author Contributions: Conceptualization, A.M.P., K.S., and S.M. (Shivani Mallishery); methodology, A.M.P., U.K.; formal analysis, A.M.L., S.M. (Simy Mathew), M.H.S., and K.P.S.; investigation, A.M.P., G.P.; data curation, A.M.P., U.K.; writing—original draft preparation, S.M. (Shivani Mallishery), K.S., A.M.P., R.M.; writing-review and editing, A.M.P., S.M. (Shivani Mallishery). All authors have read and agreed to the published version of the manuscript.

Funding: This research received no external funding.

Conflicts of Interest: The authors declare no conflict of interest.

\section{References}

1. Tomson, P.L.; Simon, S.R. Contemporary cleaning and shaping of the root canal system. Prim. Dent. J. 2016, 5, 46-53.

2. Mello, F.W.; Miguel, A.F.; Ribeiro, D.M.; Pasternak, B.; Porporatti, A.L.; Flores-Mir, C.; Andrada, A.C.; da Fonseca, L.; Garcia, R.; Dutra-Horstmann, K.L. The influence of apical extent of root canal obturation on endodontic therapy outcome: A systematic review. Clin. Oral Investig. 2019, 23, 2005-2019. [CrossRef]

3. Haapasalo, M.; Shen, Y.; Wang, Z.; Gao, Y. Irrigation in endodontics. Br. Dent. J. 2010, 54, 291-312. [CrossRef] [PubMed]

4. Siqueira, J.F.; Magalhaes, K.M.; Rocas, I.N. Bacterial reduction in infected root canals treated with $2.5 \%$ $\mathrm{NaOCl}$ as an irrigant and calcium hydroxide/camphorated paramonochlorophenol paste as an intracanal dressing. J. Endod. 2007, 33, 667-672. [CrossRef] [PubMed]

5. Hendi, S.S.; Karkehabadi, H.; Eskandarloo, A. Iatrogenic errors during root canal instrumentation performed by dental students. Iran. Endod. J. 2018, 13, 126-131.

6. Khanna, R.; Handa, A.; Virk, R.-K.; Ghai, D.; Handa, R.-S.; Goel, A. Clinical and radiographic evaluation of procedural errors during preparation of curved root canals with hand and rotary instruments: A randomized clinical study. Contemp. Clin. Dent. 2017, 8, 411-415. [PubMed]

7. Siqueira, J.F., Jr.; Pérez, A.R.; Marceliano-Alves, M.F.; Provenzano, J.C.; Silva, S.G.; Pires, F.R.; Vieira, G.C.S.; Rôças, I.N.; Alves, F.R.F. What happens to unprepared root canal walls: A correlative analysis using micro-computed tomography and histology/scanning electron microscopy. Int. Endod. J. 2018, 51, 501-508. [CrossRef]

8. Siqueira, J.F., Jr.; Rôças, I.D.; Marceliano-Alves, M.F.; Pérez, A.R.; Ricucci, D. Unpre-pared root canal surface areas: Causes, clinical implications, and therapeutic strategies. Braz. Oral. Res. 2018, 32, e65.

9. Ungerechts, C.; Bardsen, A.; Fristad, I. Instrument fracture in root canals-where, why, when and what? A study from a student clinic. Int. Endod. J. 2014, 47, 183-190. [CrossRef]

10. Alfouzan, K.; Jamleh, A. Fracture of nickel titanium rotary instrument during root canal treatment and re-treatment: A 5-year retrospective study. Int. Endod. J. 2018, 51, 157-163. [CrossRef]

11. Inan, U.; Keskin, C. Torsional resistance of ProGlider, Hyflex EDM, and One G Glide Path instruments. J. Endod. 2019, 45, 1253-1257. [CrossRef] [PubMed]

12. Koçak, M.M.; Çiçek, E.; Koçak, S.; Sağlam, B.C.; Yılmaz, N. Apical extrusion of debris using ProTaper Universal and ProTaper Next rotary systems. Int. Endod. J. 2015, 48, 283-286. [CrossRef] [PubMed]

13. Plotino, G.; Grande, N.M.; Sorci, E.; Malagnino, V.A.; Somma, F. A comparison of cyclic fatigue between used and new Mtwo Ni-Ti rotary instruments. Int. Endod. J. 2006, 39, 716-723. [CrossRef]

14. Pedulla, E.; Plotino, G.; Scibilia, M.; Grande, N.M.; De Santis, D.; Pardo, A.; Testarelli, L.; Gambarini, G. Cyclic fatigue comparison among endodontic instruments with similar cross section and different surface coating. Minerva Stomatologica 2019, 68, 67-73. [CrossRef] [PubMed]

15. Gao, Y.; Shotton, V.; Wilkinson, K.; Phillips, G.; Johnson, W.B. Effects of raw material and rotational speed on the cyclic fatigue of ProFile Vortex rotary instruments. J. Endod. 2010, 36, 1205-1209. [CrossRef]

16. International Organization for Standardization. ISO 3530-1 Dentistry-Root Canal Instruments: Part I-General Requirements and Test Methods; International Organization for Standardization: Geneva, Switzerland, 2008.

17. Bahia, M.G.; Melo, M.C.; Buono, V.T. Influence of simulated clinical use on the torsion-al behavior of nickel-titanium rotary endodontic instruments. Oral Surg. Oral Med. Oral Pathol. Oral Radiol. Endod. 2006, 101, 675-680. [CrossRef] 
18. Uygun, A.D.; Kol, E.; Topcu, M.K.; Seckin, F.; Ersoy, I.; Tanriver, M. Variations in cyclic fatigue resistance among ProTaper Gold, ProTaper Next and ProTaper Universal instruments at different levels. Int. Endod. J. 2016, 49, 494-499. [CrossRef]

19. Kaval, M.E.; Capar, I.D.; Ertas, H. Evaluation of the cyclic fatigue and torsional resistance of novel nickel-titanium rotary files with various alloy properties. J. Endod. 2016, 42, 1840-1843. [CrossRef]

20. Capar, I.D.; Kaval, M.E.; Ertas, H.; Sen, B.H. Comparison of the cyclic fatigue resistance of 5 different rotary pathfinding instruments made of conventional nickel-titanium wire, M-wire, and controlled memory wire. J. Endod. 2015, 41, 535-538. [CrossRef]

21. Gambarini, G. Cyclic fatigue of nickel-titanium rotary instruments after clinical use with low-and high-torque endodontic motors. J. Endod. 2001, 27, 772-774. [CrossRef]

22. Pirani, C.; Cirulli, P.P.; Chersoni, S.; Micele, L.; Ruggeri, O.; Prati, C. Cyclic fatigue testing and metallographic analysis of nickel-titanium rotary instruments. J. Endod. 2011, 37, 1013-1016. [CrossRef] [PubMed]

23. Council on Dental Materials, Instruments, and Equipment. Revised ANSI/ADA specifications No. 28 for root canal files and reamers, type K, and No. 58 for root canal files, type H (Hedstrom). J. Am. Dent. Assoc. 1989, 118, 239-240. [CrossRef]

24. Plotino, G.; Grande, N.M.; Cordaro, M.; Testarelli, L.; Gambarini, G. A review of cyclic fatigue testing of nickel-titanium rotary instruments. J. Endod. 2009, 35, 1469-1476. [CrossRef] [PubMed]

25. Sousa, J.; Basto, J.; Roseiro, L.; Messias, A.; dos Santos, J.M.; Palma, P. Evaluation of the cyclic fatigue of 3 file systems used in mechanized instrumentation. Port. J. Stomatol. Dent. Med. Maxillofac. Surg. 2015, 56, 239-245. [CrossRef]

26. Palma, P.J.; Messias, A.; Cerqueira, A.R.; Tavares, L.D.; Caramelo, F.; Roseiro, L.; Santos, J.M. Cyclic fatigue resistance of three rotary file systems in a dynamic model after immersion in sodium hypochlorite. Odontology 2019, 107, 324-332. [CrossRef] [PubMed]

27. Keleş, A.; Eymirli, A.; Uyanık, O.; Nagas, E. Influence of static and dynamic cyclic fatigue tests on the lifespan of four reciprocating systems at different temperatures. Int. Endod. J. 2019, 52, 880-886. [CrossRef]

28. Li, U.-M.; Lee, B.-S.; Shih, C.-T.; Lan, W.-H.; Lin, C.-P. Cyclic fatigue of endodontic nickel titanium rotary instruments: Static and dynamic tests. J. Endod. 2002, 28, 448-451. [CrossRef]

29. Capar, I.D.; Ertas, H.; Arslan, H. Comparison of cyclic fatigue resistance of nickel-titanium coronal flaring instruments. J. Endod. 2014, 40, 1182-1185. [CrossRef]

30. Pawar, A.; Pawar, B.A.; Bhardwaj, A.; Luke, A.M.; Metzger, Z.; Kfir, A. Apical Debris Extrusion by Adaptive Root Canal Instrumentation in Oval Canals: Full-Sequence SAF System vs. the XP-Endo Shaper Plus Sequence. Appl. Sci. 2020, 10, 5684. [CrossRef] 